\title{
Nonlinear Analysis of Reinforced Concrete Frame Subjected to Fire
}

\author{
Zhongbao $\mathrm{Ye}^{1}$ \\ University of Science and Technology of China \& \\ Anhui Xinhua University, \\ China, Hefei

\section{RuiYuan Huang ${ }^{2}$} \\ University of Science and Technology of China, China, \\ Hefei
}

\begin{abstract}
Reinforced concrete frames are one of most popular structures used in the world, but the research on their fire is at primary stage. In this thesis, the non-liner analysis of reinforced concrete frames at elevated temperature was analyzed by ANSYS, which included calculations and analysis of temperature field, structural deformation, and post-fire ultimate loadings, it was investigated in this paper with ANSYS. The analysis results indicate that the reinforced concrete frame members undergo internal force redistribution under a fire, and the super position of constraint internal forces with external loads causes destroy in beams and columns. Finally, the fire-resistance design of concrete structures was also discussed.In this thesis, by IS0834 Standard temperature-time curve. At the same time, the temperature field, the deformation law at high temperatures are also put forward. The temperature field is simulated using ANSYS, and the calculated results agree with test results. In a one compartment fire, obvious deformation of structural occurs lead to internal forces changed during fire, and the thermal expansion of the heated beams and columns is the main agitator in a one compartment fire. The degree of redistribution of the moment of the end of column is larger than the end of beam. Fire location has more influences on the fire resistance of reinforced concrete frame because the part of the structure at ambient temperature exerts different restrictions on the heated part.In the end, several suggestions are presented on the applicable design method of reinforced concrete frame in the fire.
\end{abstract}

Keywords-reinforced

concrete

frame;

deformation ;stress; non-liner analysis; fire resistance

\section{ANALYSIS MODEL}

As indicated in Fig .1, the three layer three span reinforced concrete plane frame is the analysis model. According to the given engineering load value ${ }^{[1]}$, the reinforcement Structure design of beams, columns is calculated by PKPM software. Prior to warming up, the load (dead load and live load) is applied to the analysis model. Temperature load is calculated according to standard temperature curve in ISO834.

\author{
Yalong Jiang ${ }^{3}$ \\ Anhui Xinhua University, China, Hefei
}

$\operatorname{LinLv}^{4}$

Coal Industry Hefei Design and Research Institute. China, Hefei

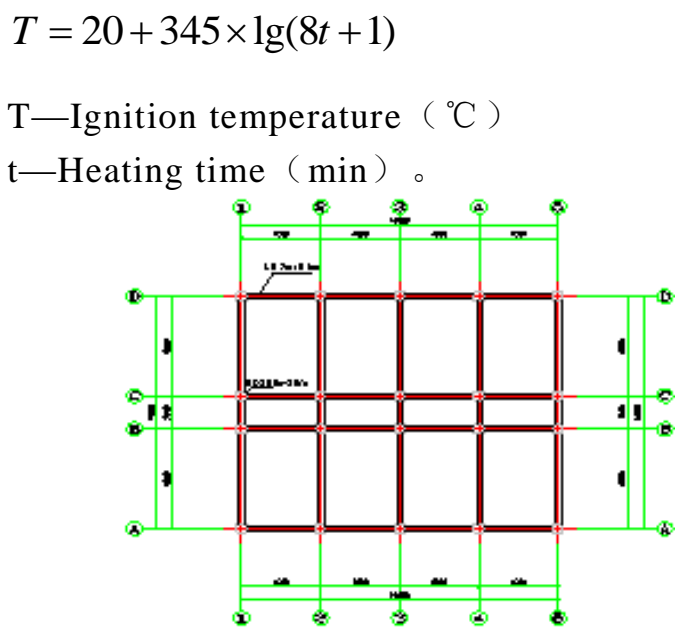

Figure 1. calculation model

II. STRUCTURE CALCULATION OF THE VALIDATION FIELD

The ANSYS results can be obtained, that some nodes corresponding temperature values at different moments are in the Fig . 2 $\sim 3$.

As indicated in Fig. $2 \sim 3$, different nodes at different time temperature changes to show the similarity law. ANSYS calculated results with the literature ${ }^{[2]}$ experimental agreement. ${ }^{[3.4 .5]}$

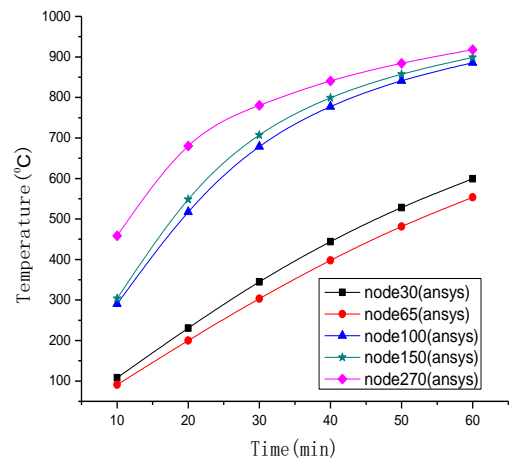

Figure 2. node time-temperature curves 


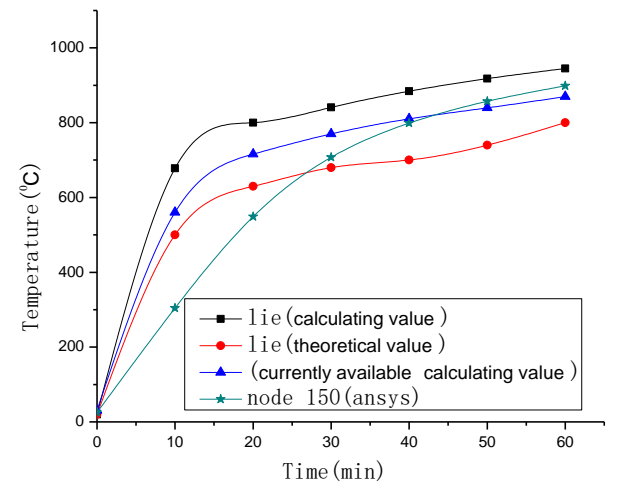

Figure 3. node time-temperature curves

III. NONLINEAR ANALYSIS OF PERFORMANCE OF REINFORCED CONCRETE FRAME STRUCTURE IN THE FIRE

1).To establish the finite element model of reinforced concrete frame structure

When the author calculates static structural analysis and thermal-structure coupling, concrete model will use the SOLID65 unit, reinforced by LINK8 unit.

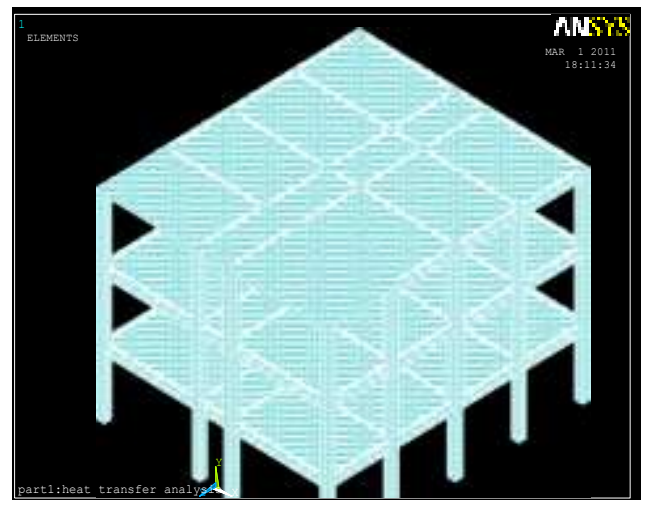

Figure 4 finite element model and the model divided

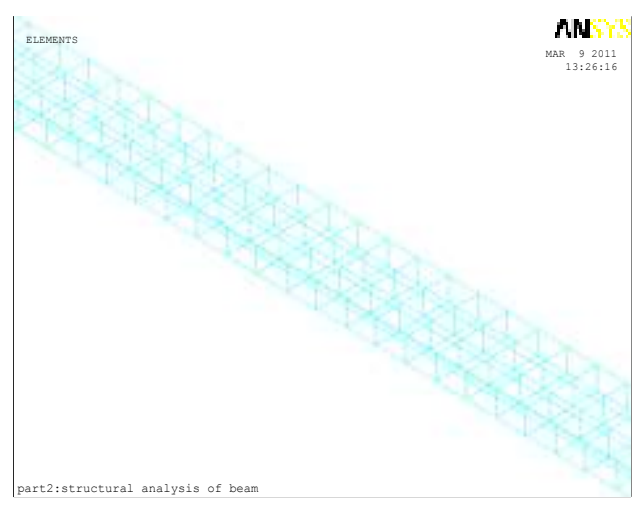

Figure 5 beams tendon and stirrups
2)Room temperature deformation and internal force analysis framework

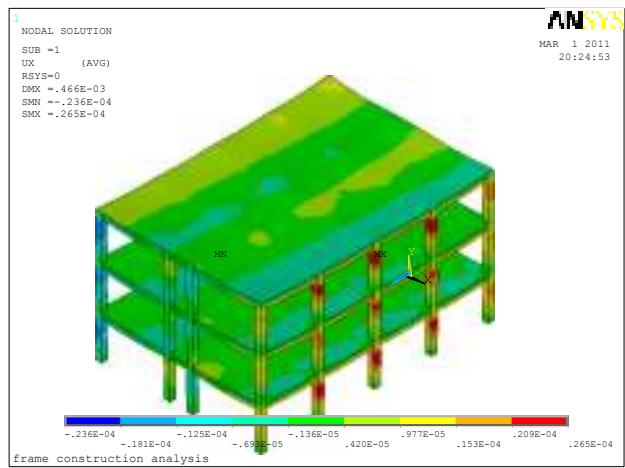

Figure.6 X direction deformation cloud

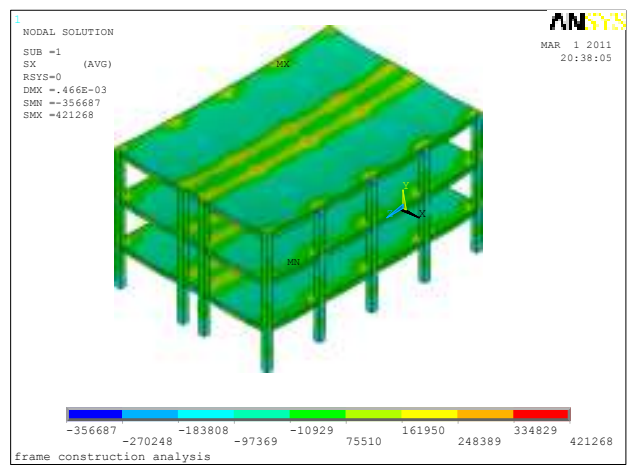

Figure 7. X direction stress cloud

3)The local temperature field of concrete frame structure

a)Thermal analysis

As indicated in Fig .9, according to the ANSYS results obtained some key sections related in different time, such as the bottom of the column, column, column end, temperature data of beam end, and beams.

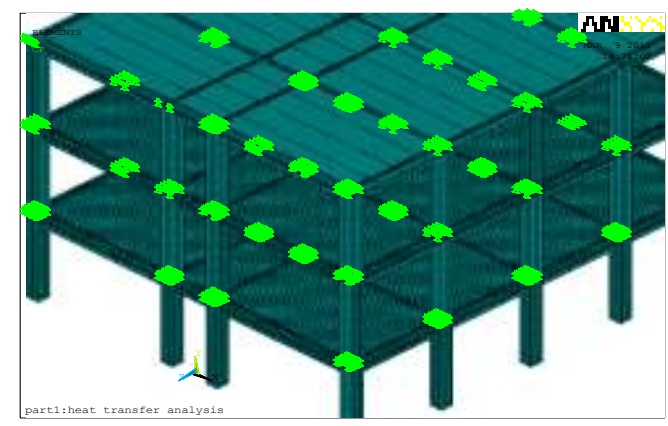

Figure 8 Coupling of the beams and columns with the coordinates of nodes 


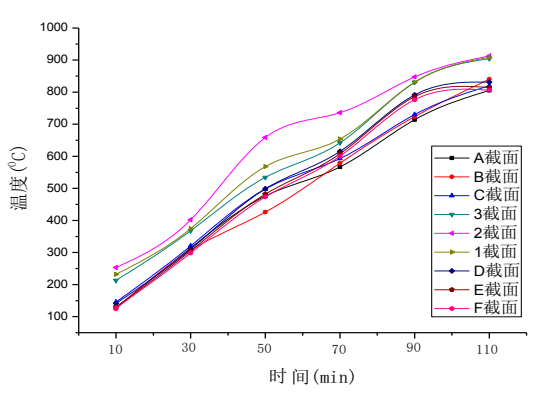

Figure 9.Time-temperature curves

4) The local high temperature deformation and internal force of reinforced concrete frame structure

a).Study on deformation of local high temperature concrete frame

Study on the deformation of beams

As indicated in Fig . $10 \sim 11$, when $t=110 \mathrm{~min}$, the deformation of the beam, beam, column time displacement curve.

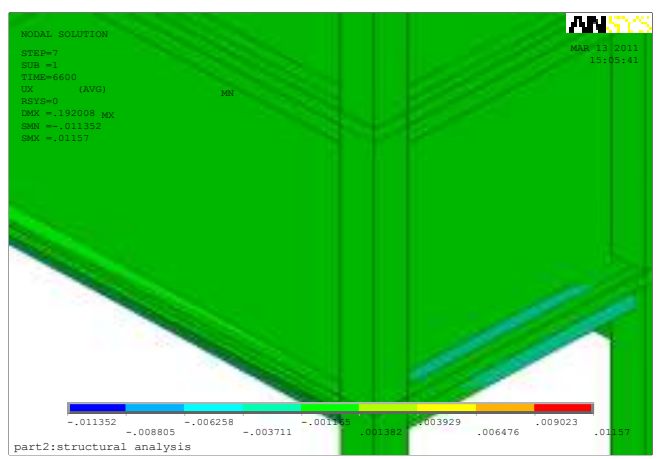

Figure 10. deformation of the beam in the $\mathrm{X}$ direction cloud at time 110 minute

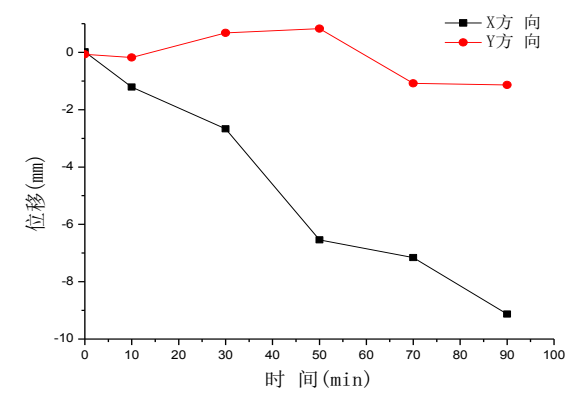

Figure.11.beam end time-displacement curves

By the calculation results:

(1)With the increase of temperature, the horizontal displacement of the upper frame beam, column $\mathrm{X}$ in the direction increase;

(2)Transient thermal strain has great effect on the low strength concrete deformation ${ }^{[6]} ; \mathrm{Y}$ direction column expansion deformation displacement is smaller than the beam;

(3) As indicated in the curve of the deformation of frame beam, the beam deflection at room temperature is relatively smaller, to high temperatures upward to downward expansion of larger deformation damage, beam span of vertical expansion displacement will occur rapidly after the downward deflection greatly, resulting in high temperature of the beam damage;

(4)According to the specification ${ }^{[7]}$, the reinforced beams deflection limit, when the heating time of 70 $80 \mathrm{~min}$, near the beam end into the plastic deformation, plastic hinge and produce plastic failure.

b) Study on deformation of column

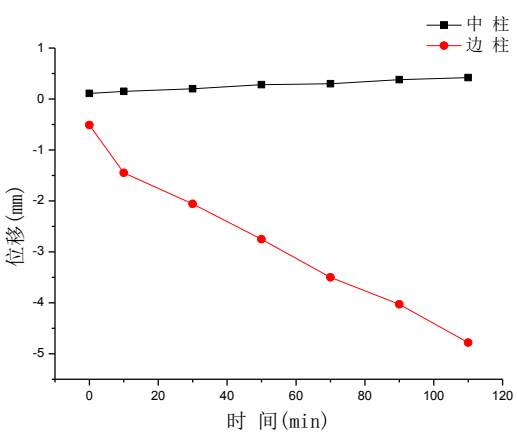

Figure 12. The column time-displacement curves

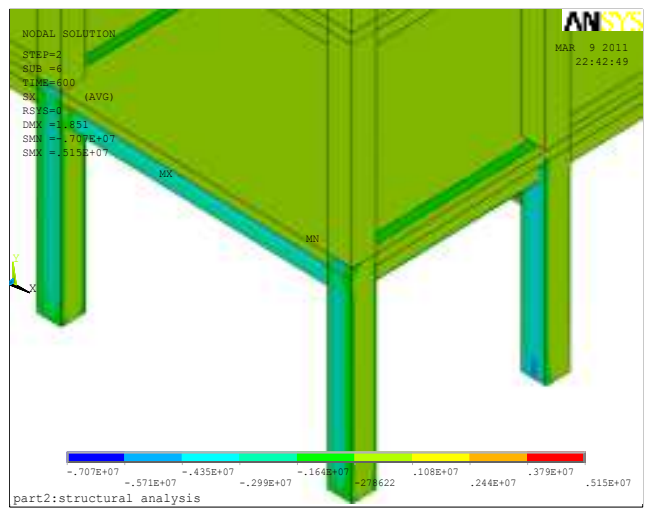

Figure 13. X-direction stress cloud at time 10 minute

As indicated in the above Fig .12. Fig .13:

(1)The deformation process of frame column: compression deformation at Room temperature expansion to the vertical deformation at high temperature is too large to produce plastic deformation; deformation performance of frame structure column and single column temperature are identical;

(2)The axial column force is larger than the side column in the frame structure, but the axial side column expansion is larger than the column;

(3)The first column displacement along the $\mathrm{Y}$ positive increases and then decreases, while the displacement column top height is always less than the middle column, because the axial compression ratio of column is larger than the side column. 
c).Study on changes of internal force of reinforced concrete frames

Frame structure in $\mathrm{X}$ direction, $\mathrm{XY}$ direction shear stress nephogram is indicated in the Fig . $14\llcorner 15$.

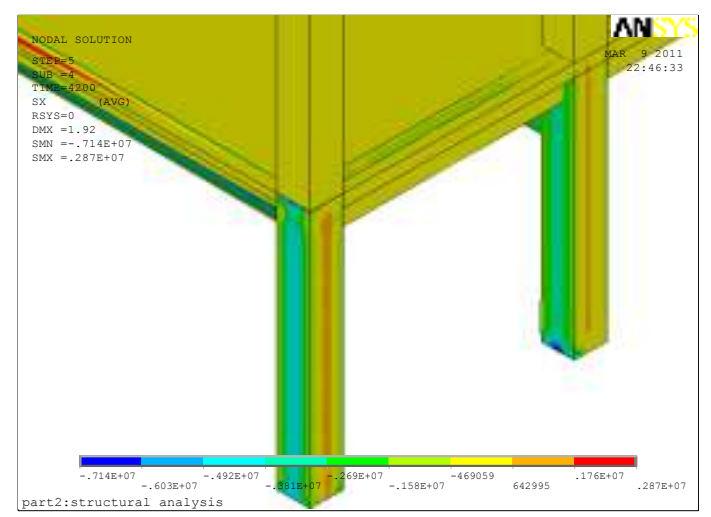

Figure 14. X-direction stress cloud at time 70 minute

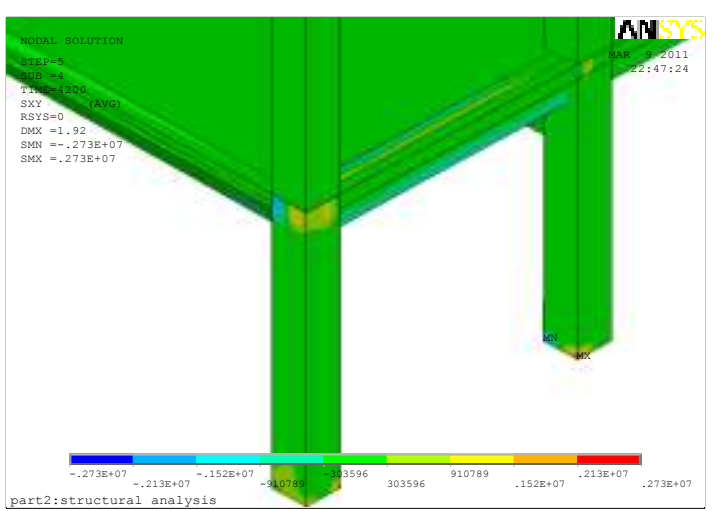

Figure 15. the XY direction scissors stress cloud at time 70 minute

\section{d).The moment of beam and column}

(1)The moment of the beam end

The moment of beam end analysis by force curves available: the absolute moment value of the beam end at fire 50min growth rate is rapid, internal force changes the slope of the curve is larger, with the fire duration time - temperature increase, the moment of beam end growth slows. There is a peak value in the fire about 50-70min.

(2) The moment of the column end

The moment of column frame structure increases with the fire duration time and temperature increasing, until the structure of plastic deformation of plastic hinge and cause the structure damage. Due to expansion deformation of beam and column heating, so that the post by the axial temperature load into high temperature obviously affected by eccentric load. The moment Change of column end at high temperature is larger than the internal force change of the end of beam mid-span of beam section.

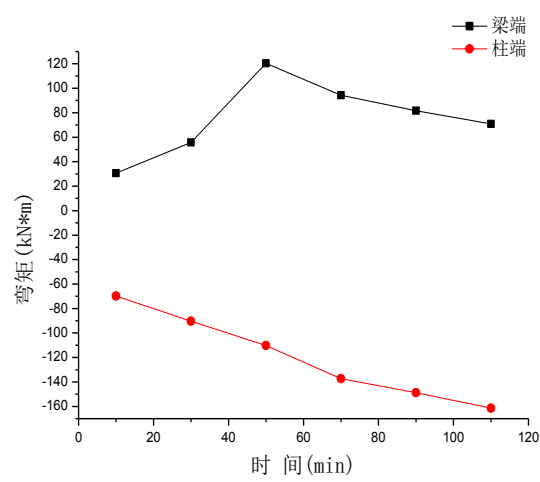

Figure 16. beams and columns time-moment curves

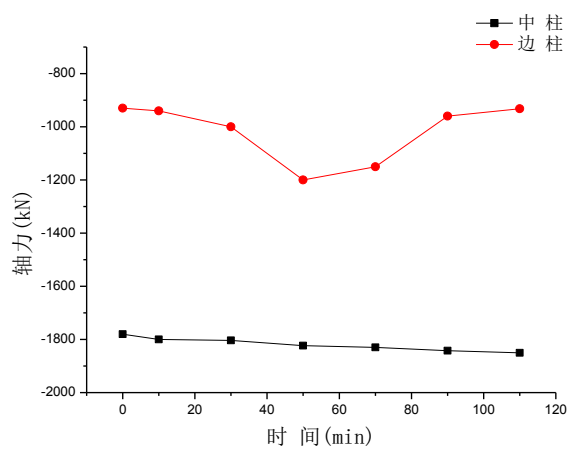

Figure 17 the column time-axial force curves

\section{e).Axial force of beam and column}

As indicated in the above Fig .:

(1)The column axial force is smaller than the larger axial force of column under normal weight action. At high temperature, deformation of the structure is coordinated. So the side column expansion deformation is larger under local fire. The axial force of side column increases with deformation, but not infinitely increase, it will be slightly decreased at temperature of 70-80min, and the variation of axial force in the column is relatively smaller.

\section{f). Shear force of beam and column}

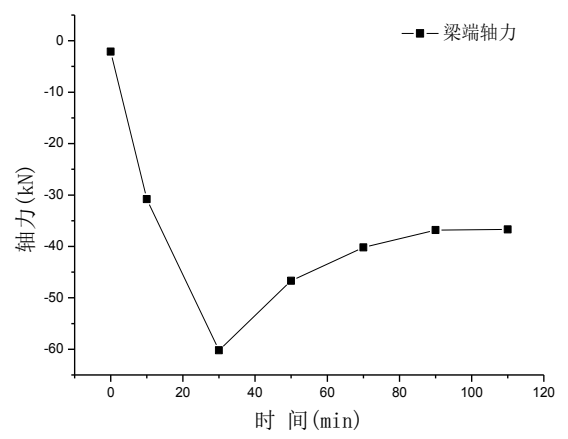

Figure 18 beam time-axial force curves 


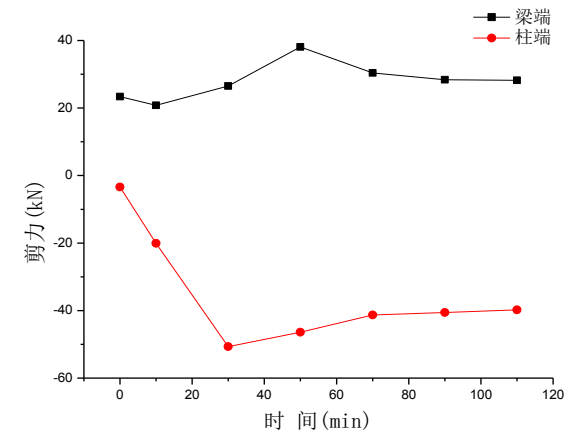

Figure 19 beams and columns time-Shear curves As indicated in the above Fig .:

(1)The change of shear force of frame beam is smaller at high temperature, and the change of shear force of frame column is larger, it is due to the beam after fire expansion deformation.

(2)The shear force value of Frame beam and column is maximum of the heating time about $50-70 \mathrm{~min}$ is largest, with a similar consistency

(3)The shear force value of Frame beam and column is influenced by the moment value. ${ }^{[8.9 .10]}$

\section{CONCLUSION}

(1)Distribution of temperature field of the members: The initial temperature difference of the member and the outside temperature can reach $150-250{ }^{\circ} \mathrm{C}$. With the extension of heating time, the temperature difference is gradually reduced to $20-30{ }^{\circ} \mathrm{C}$. The ambient temperature is higher than the temperature of the member;

(2)The distribution of the temperature field, structural deformation, the variation regularity of the internal forces, stress characteristics of the frame structure in the fire are analyzed by ANSYS. Axial force of the beam has a very obvious change.

(3)The internal force change of frame structure is occurred in local fire. Under the effects of fire the axial force change of column is more slowly, but the variation of axial force of beam is very obvious; the heating process, the change of bending moment of column sections is various. After the heating, the internal force distribution of the structure is similar to the distribution of internal force of the structure under horizontal load.
(4)As indicated in the curves of the deformation and stress, the beam span, the end of beam and column, column end is the stress concentrated area, and easy to form plastic hinges weak section. In structural design of fire resistance should be adopted to increase the column and beam rotation ability measures, to increase the ductility of the structure, so that it can increase the ability against changes of deformation and internal force. These parts need to be strengthened through various measures in structural design of fire resistance.

\section{ACKNOWLEDGEMENT}

1.The project supported by National Natural Science Foundation of China (No.11402266);

2.Supported by the Fund of the State Key Laboratory of Disaster Prevention \& Mitigation of Explosion \& Impact(PLA University of Science and Technology) (No. DPMEIKF201401).

\section{REFERENCES}

[1]Code for design of concrete structures[M]. GB50010-2010, China Architecture \& Building Press,2010

[2]Xudong SHI, Zhenghai GUO. Experimental investigation of behavior of reinforced concrete frames at elevated temperature [J].China Civil Engineering Journal, 2000 ,33(1) : 36-45

[3]T. T. Lie , R. J . Irwin. Fire resistance of steel columns filled with bar reinforced concrete $[\mathrm{J}]$. Journal of Structural Engineering , 1995 , 121(5): 797-805

[4]Lie,T.T..Fire resistance of circular steel columns filled with bar reinforced concrete .Journal of Structure Engineering .1994,120(5).

[5]Gordon M,E.Cooke. Behavior of precast concrete floor slabs exposed to standard fire. Fire Safety Journal.2009,6:459-475

[6]Guangyong WANG, Chuanguo FU, Theoretical and experimental study on fire resistance of reinforced concrete frame structure [J]. Journal of Southwest JIAOTONG University, 2009,5(3) : $12-15$

[7]Code for design of concrete structures [M]. GB50010-2010, China Architecture \& Building Press,2010

[8]Zhoudao,LU, Analysis of reinforced concrete beam on fire response [D]. Doctoral Dissertation of Tongji University, 1989

[9]Karamoko Sidibé, Frédéric Dup rat, Michel Pinglot, Bernard Bourret. Fire safety of reinforced concrete columns [ J ]. ACI Structural Journal, 2000, 97 (4) : 642 - 647

[10]Li Long-yuan, PURKISS John.Stress-strain constitutive equations of concrete material elevated temperatures. Fire Safety Journal . 2005, 40: 669-686 